\title{
Impact of Inflammatory Bowel Disease upon Growth in Children and Adolescents
}

\author{
V. Moeeni ${ }^{1}$ and A. S. Day ${ }^{1,2}$ \\ ${ }^{1}$ Department of Paediatrics, University of Otago, Christchurch, Riccarton Avenue, Christchurch 8140, New Zealand \\ ${ }^{2}$ Department of Paediatrics, Christchurch Hospital, Christchurch 8140, New Zealand
}

Correspondence should be addressed to A. S. Day, andrew.day@otago.ac.nz

Received 26 January 2011; Accepted 10 March 2011

Academic Editors: R. S. Trompeter and B. Vasarhelyi

Copyright ( 2011 V. Moeeni and A. S. Day. This is an open access article distributed under the Creative Commons Attribution License, which permits unrestricted use, distribution, and reproduction in any medium, provided the original work is properly cited.

The inflammatory bowel diseases (IBDs) are chronic inflammatory processes affecting the gastrointestinal tract. When diagnosed in childhood and adolescence, IBD almost always impacts adversely upon the nutritional state of the patient. Weight loss and impaired linear growth may be present at diagnosis or subsequently. Further potential nutritional consequences in childhood IBD include malnutrition, anaemia, osteopaenia, and delayed puberty. Understanding the nutritional aspects of IBD is paramount in growing children, especially those entering and advancing through puberty. This paper focuses upon the nutritional impacts of IBD in children and adolescents.

\section{Introduction}

The inflammatory bowel diseases (IBDs) are chronic illnesses affecting the gastrointestinal tract: they predominantly comprise Crohn's disease (CD) and ulcerative colitis (UC). Although CD and UC share some features, they have distinctive endoscopic and histological characteristics and disease patterns [1]. Furthermore, the clinical manifestations and outcomes of these two conditions vary. At present, there are no specific medical cures for CD and UC: current therapies aim to control the disease and prevent adverse outcomes [1].

$\mathrm{CD}$ and UC may present at any age. Although IBD is uncommon in the first decade of life, presentation in infancy is well recognized. IBD is more common in the second decade, particularly in adolescence $[2,3]$. There are clear demonstrations of increasing incidence of IBD around the world over the last decades, with increased rates also noted in areas with previous very low rates [3-8]. The changing incidence of IBD has also been noted in paediatric populations, with particular increases in $\mathrm{CD}[9,10]$.

A history of weight loss or poor weight gain is commonly recorded at the time of diagnosis with IBD in children and adolescents. Poor linear growth may also be evident at the initial assessment, leading to growth failure in some. Growth impairment is typically more prominent in CD than UC [1]. Impaired nutrition may lead onto short- and long-term consequences that include delayed puberty, micronutrient deficiencies, impaired adult height, and bone disease. Regular monitoring and detailed attention to nutritional support remains a central facet of the management of children and adolescents with IBD. This paper will focus on the impact of IBD upon the nutritional state of children and adolescents and will highlight recent advances in this area.

\section{Altered Growth Patterns in Paediatric IBD}

2.1. Weight in Children with IBD. Numerous cohort studies have demonstrated weight loss or poor weight gains at the time of initial diagnosis of IBD. Reports indicate that most children with CD have a history of weight loss or absent weight gains prior to diagnosis. In a cohort of 386 Canadian children diagnosed with $\mathrm{CD}$ over a ten-year period, $80 \%$ had a history of weight loss [1]. A retrospective chart review of a cohort of 61 children diagnosed with CD at Sydney Children's Hospital, Sydney, Australia showed that 51\% had a history of weight loss at the time of diagnosis [11]. In a prospective UK study of 379 paediatric CD patients, $58 \%$ had 
weight loss at diagnosis and $27 \%$ had weight $<3$ rd centile [12]. Weight loss tends to be seen less commonly in children with UC-up to $31 \%$ of 172 children in the same UK cohort had a history of weight loss at diagnosis [12].

Maintaining appropriate weight gain also continues to be an ongoing issue after diagnosis. In a cohort of 41 children with longstanding $\mathrm{CD}$ recruited to assess dietary intakes and nutrition, the 18 children with active $\mathrm{CD}$ had lower mean $Z$ scores for weight, height, and BMI than the 23 children currently in remission [13].

The reasons for altered weight gains are likely multifactorial, with decreased caloric intake being the most common [14-19]. Poor intake may be the consequence of the anorexic effects of proinflammatory mediators, such as interleukin$1 \beta$ or Tumour necrosis factor (TNF) $-\alpha[20,21]$ or result from early satiety, pain, or nausea. Pain associated with eating, leading to poor tolerance of foods, and the fear of diarrhoea following meals are additional reported reasons for reduced intake. Small bowel involvement may lead to disaccharide intolerance resulting in shorter gut transit times, pain, and exacerbation of diarrhoea. Malabsorption of food components and the diversion of calories to sites of gut inflammation may be further contributing factors leading to impaired growth.

2.2. Impaired Linear Growth in IBD. In addition to presentation with loss of body weight or poor weight gains, children also commonly have altered patterns of linear growth. Decreased height velocity was noted in up to $88 \%$ of a group of 50 children at the time of diagnosis with $\mathrm{CD}$ - a number of these children had impaired linear growth prior to the onset of gut symptoms [22]. Impaired linear growth tends to be more pronounced in boys than girls-this is principally related to the male pubertal growth spurt occurring later and lasting longer. Boys may also be more aware of variations in height. Furthermore, the limited duration of puberty limits the time before impaired linear growth becomes irreversible $[23,24]$.

$\mathrm{CD}$ is commonly associated with impaired linear growth either at diagnosis or as a long-term outcome [22-29]. Some earlier studies reported that despite growth retardation occurring during teenage years, many of these patients eventually achieved heights within the normal range for the general population [30,31]; however, the genetic component of linear growth was not considered in these studies. Markowitz et al. [24] retrospectively assessed the growth patterns of 48 adults with IBD (38 with CD and 10 with UC: $73 \%$ male) who had previously been diagnosed during childhood. These investigators used two height prediction methods and employed the American National Centre for Health Statistics growth charts: $31 \%$ of this group were found to have permanently impaired linear growth. In their study of 132 children and young adults aged between 5-25 years, Sentongo and colleagues [28] argued that height adjusted for genetic potential was a more powerful way of assessing height status in children with CD. In these children, the $Z$ scores based on adjusted heights were significantly lower than $Z$ scores based on measured heights. Again, males in this group were most severely affected, with the average adjusted height for age $Z$ score one standard deviation less than expected.

Lee et al. [30] recently undertook a prospective assessment of height in 295 children with CD and UC who had been diagnosed between 2002 and 2008 in Boston, USA. Twenty-two percent of these children $(90 \%$ of whom had $\mathrm{CD}$ ) had linear growth impairment (height for age $Z$-score of -1.64 or less) documented on one or more measurements from the time of diagnosis. The final mean adult height $Z$ score in this cohort was -0.39 .The main predictors of final adult height in this cohort were found to be lower parental height and the patient's lowest height $Z$ score.

A recent British study also assessed the final adult height of a group of 23 individuals who had been diagnosed with CD prior to their 16th birthday [31]. This group had a final adult height $Z$ score of -0.29 : very similar to that observed in the North American study [30]. The mean final height of these patients was $2.4 \mathrm{~cm}$ less than the parental or target height (range of -20.0 to $+9.0 \mathrm{~cm}$ ). Twenty percent of the group had a final adult height greater than $8.0 \mathrm{~cm}$ below their target height. Jejunal disease and the length of symptoms prior to diagnosis (diagnostic delay) were predictive factors of final adult height in this cohort. In this cohort, exposure to corticosteroids, surgical intervention, and parental height were not predictive factors. Jejunal disease location has previously been suggested to be associated with linear growth impairment [32, 33].

A Danish population-based assessment of growth in children with IBD highlights the differential effects of CD and UC upon growth [34]. Forty-four children with CD were included in this study, along with 50 with UC and four with IBD unclassified (IBDU). The growth data was normalised using Danish reference values. The children with UC had similar height and BMI scores for age to control data. In contrast, the children with $\mathrm{CD}$ had height for age $Z$ score of -0.77 : also they were shorter than the children with UC $(P=.005)$. Fifty percent of the children with $C D$ had a height less than the 25th centile for age.

\subsection{Factors Influencing Linear Growth in Children with IBD.} Numerous factors impact upon impaired linear growth in IBD. Several gut-derived mediators likely impact negatively upon linear growth [35]. TNF- $\alpha$ inhibits chondrocyte activity in growth plates [36]. Interleukin (IL)-6 may have direct effects leading to growth failure [37]. Elegant studies in rodent models show that approximately $40 \%$ of growth impairment is consequent to the effects of inflammatory proteins, especially IL-6 $[38,39]$. Further, TNF- $\alpha$ and IL-6 both independently suppress levels of Insulin-like Growth Factor (IGF)-1, a critical mediator of the local actions of growth hormone [40].

Male gender, age at diagnosis, disease location, disease severity, and treatment modality may also all affect final height acquisition. Severity of disease (defined by various measures such as steroid requirements, use of immunosuppressives, and cumulative period of hospitalisation) was correlated with impaired weight and height gains in a cohort of Israeli children [41]. Location of disease in these children 
was also weakly associated with growth impairment. Interestingly, the presence of the NOD2 genotype was not associated with impaired weight or linear growth, despite associations between ileal location and mutations in this gene.

A recent report highlighted the importance of genetic influences upon linear growth in children with IBD. In a cross-sectional study, 951 subjects, comprising 317 CD patient-parent trios, were genotyped for growth-associated genetic loci and CD-associated loci [42]. Linear growth impairment in the children with CD was associated with a polymorphism in the dymeclin gene DYM (Odds Ratio 3.2).

2.4. Pubertal Delay in IBD. Delayed puberty is also frequently observed in children with IBD, especially those with CD $[43,44]$. In one cohort of children diagnosed with CD prior to the onset of puberty, menarche was noted to occur at or later than 16 years of age in almost three-quarters of the girls [43]. Delayed pubertal development is more common in children who have never achieved remission or who have had repeated disease relapses [44], emphasizing the interactions between disease control and growth in children.

2.5. Overweight and Obesity in IBD. Although the most concern in regard to the nutritional impact of IBD in children is towards under nutrition, some children with IBD may be overweight (BMI > 85\%) and/or obese (BMI > 95\%). In a cohort of 166 children with newly diagnosed IBD from Wisconsin, USA, $12.1 \%$ of those with CD and $17.6 \%$ of those with UC were overweight/obese [45].

In a group of 1598 American children with known IBD, the prevalence of overweight and obese status was found to be $23.3 \%$ overall [46]. A higher rate $(30 \%)$ was also seen in the UC group. Overweight/obesity in this multicentre cohort was associated with African-American ethnicity and Medicaid insurance status. In addition, a prior surgical intervention was linked with overweight/obese status in the children with $\mathrm{CD}$, suggesting that the presence of over nutrition may be associated with a more severe disease course.

2.6. Influence of Medical Therapies upon Growth in Children with IBD. Medical therapies may impact negatively upon aspects of growth in children with IBD. Corticosteroids, for example, can lead to numerous side effects, including nutritional consequences [47]. Increased appetite and fluid retention are commonly seen after commencement of steroids. Consequently, apparent improvements in weight during a course of corticosteroids may reflect fluid retention and not an improvement in the underlying nutritional status. Steroids also lead to enhanced bone resorption and decreased new bone formation, adversely affecting bone health [48, 49]. Further, daily corticosteroid therapy can suppress IGF1 activity, contributing to inhibition of linear growth and impaired final height [50].

Some medical therapies may compromise micronutrient status. Sulphasalazine may lead to folate malabsorption; however, daily folate supplementation does not appear necessary [51]. Folate supplementation is required, however, when Methotrexate is used to avoid folate deficiency due to the inhibition of the conversion of folate to the active moiety tetrahydrofolate [52]. Cholestyramine, when required for bile-salt diarrhea, may impede absorption of vitamin B12.

In contrast, some interventions, such as exclusive enteral nutrition (EEN) and biological therapies, have numerous positive nutritional effects. EEN is a specific nutritional therapy that involves the administration of a liquid formula as sole nutritional intake (with exclusion of normal diet) for up to 8 weeks [53]. This therapy is efficacious in active $\mathrm{CD}$, with remission rates similar to those seen with corticosteroids [54]. EEN leads to positive improvements in weight and linear growth, normalization of IGF-1 levels, and stabilization of bone turnover [53]. EEN is also associated with improved vitamin D status compared to children treated with corticosteroids [55].

Biological therapies in children with $\mathrm{CD}$ also clearly impact positively upon growth [56-60]. Walters et al. [58] examined the growth patterns of 32 children treated with Infliximab (28 responders) for severe CD. These children had improved height velocity, and height centile increases after Infliximab, with timing prior to early puberty being important. Malik et al. [59] found that improvements in linear growth after Infliximab can be independent of pubertal status and reduction in corticosteroids. These effects of infliximab in children with CD may be due to improved inflammation with mucosal healing or due to direct effects upon growth hormone and IGF-1 signaling [60]. In a recent report, Crombé et al. [61] demonstrated that the height $Z$ scores of a group of 41 French children responding to Infliximab improved from $-0.57 \pm 1.18$ to $-0.25 \pm 0.99$ ( $P=.04)$ over the period of followup. In contrast, those children not responding to this drug had no catch up growth.

2.7. General Management of Growth in Children with CD. Given the frequency and patterns of disturbed growth in children with IBD (and especially those with CD), the management of such children must include a clear and constant focus upon growth and nutrition. Resumption of normal growth patterns should be seen as an element of the success of therapy.

Baseline assessment of nutritional status at the time of diagnosis should include detailed standard anthropometry, along with clear documentation of preceding growth patterns and familial growth patterns (especially parental heights). Furthermore, close monitoring of growth during followup must be considered a mandatory part of the multidisciplinary care of children and adolescents with IBD.

\section{Conclusion}

There is now plentiful evidence demonstrating the significant impact of IBD upon growth and nutrition in children. Recent studies have helped to demonstrate the importance of nutritional, inflammatory, and genetic factors in growth outcomes. Consequently, a key aspect of the ongoing management of children and adolescents with IBD should be the close and constant attention to growth. 


\section{References}

[1] A. M. Griffiths and J.-P. Hugot, "Crohn disease," in Pediatric Gastrointestinal Disease, A. Walker, O. Goulet, R. E. Kleinman et al., Eds., BC Decker, Ontario, Canada, 4th edition, 2004.

[2] V. Binder, "Epidemiology of IBD during the twentieth century: an integrated view," Best Practice and Research: Clinical Gastroenterology, vol. 18, no. 3, pp. 463-479, 2004.

[3] A. M. Griffiths, "Specificities of inflammatory bowel disease in childhood," Best Practice and Research: Clinical Gastroenterology, vol. 18, no. 3, pp. 509-523, 2004.

[4] T. D. Walters, J. Critch, P. Kundhal, P. Sherman, and A. M. Griffiths, "Epidemiology of pediatric IBD in the Greater Toronto Area," Journal of Pediatric Gastroenterology and Nutrition, vol. 39, supplement 1, p. S330, 2004.

[5] A. Auvin, F. Moline, C. Gower-Rousseau et al., "Incidence and presentation of paediatric IBD at diagnosis. A prospective population-based study in northern France (1988-1999)," Journal of Pediatric Gastroenterology and Nutrition, vol. 39, supplement 1, p. S331, 2004.

[6] D. Knafelz, B. Papdatou, A. Barabino et al., "Epidemiology of paediatric inflammatory bowel disease in Italy: results from the national register," Journal of Pediatric Gastroenterology and Nutrition, vol. 39, supplement 1, p. S282, 2004.

[7] H. Hildebrand, Y. Finkel, L. Grahnquist, J. Lindholm, A. Ekbom, and J. Askling, "Changing pattern of paediatric inflammatory bowel disease in northern Stockholm 1990 2001," Gut, vol. 52, no. 10, pp. 1432-1434, 2003.

[8] B. J. Kim, S. M. Song, K. M. Kim et al., "Characteristics and trends in the incidence of inflammatory bowel disease in Korean children: a single-center experience," Digestive Diseases and Sciences, vol. 55, no. 7, pp. 1989-1995, 2010.

[9] N. Phavichitr, D. J. S. Cameron, and A. G. Catto-Smith, "Inflammatory bowel diseases: increasing incidence of Crohn's disease in Victorian children," Journal of Gastroenterology and Hepatology, vol. 18, pp. 332-332, 2003.

[10] E. I. Benchimol, K. J. Fortinsky, P. Gozdyra et al., "Epidemiology of pediatric inflammatory bowel disease: a systematic review of international trends," Inflammatory Bowel Diseases, vol. 17, pp. 423-439, 2011.

[11] D. A. Lemberg, C. M. Clarkson, T. D. Bohane, and A. S. Day, "Role of esophagogastroduodenoscopy in the initial assessment of children with inflammatory bowel disease," Journal of Gastroenterology and Hepatology, vol. 20, no. 11, pp. 1696-1700, 2005.

[12] A. Sawczenko and B. K. Sandhu, "Presenting features of inflammatory bowel disease in Great Britain and Ireland," Archives of Disease in Childhood, vol. 88, no. 11, pp. 995-1000, 2003.

[13] R. Pons, K. E. Whitten, H. Woodhead, S. T. Leach, D. A. Lemberg, and A. S. Day, "Dietary intakes of children with Crohn's disease," British Journal of Nutrition, vol. 30, pp. 1-6, 2009.

[14] E. Seidman, N. LeLeiko, M. Ament et al., "Nutritional issues in pediatric inflammatory bowel disease," Journal of Pediatric Gastroenterology and Nutrition, vol. 12, no. 4, pp. 424-438, 1991.

[15] B. S. Kirschner, J. R. Klich, and S. S. Kalman, "Reversal of growth retardation in Crohn's disease with therapy emphasizing oral nutritional restitution," Gastroenterology, vol. 80, no. 1, pp. 10-15, 1981.

[16] B. S. Kirschner, O. Voinchet, and I. H. Rosenberg, "Growth retardation in inflammatory bowel disease," Gastroenterology, vol. 75 , no. 3, pp. 504-511, 1978.
[17] D. G. Kelts, R. J. Grand, and G. Shen, "Nutritional basis of growth failure in children and adolescents with Crohn's disease," Gastroenterology, vol. 76, no. 4, pp. 720-727, 1979.

[18] K. J. Motil, R. J. Grand, C. J. Maletskos, and V. R. Young, "The effect of disease, drug, and diet on whole body protein metabolism in adolescents with Crohn disease and growth failure," Journal of Pediatrics, vol. 101, no. 3, pp. 345-351, 1982.

[19] K. J. Motil, S. I. Altchuler, and R. J. Grand, "Mineral balance during nutritional supplementation in adolescents with Crohn disease and growth failure," Journal of Pediatrics, vol. 107, no. 3, pp. 473-479, 1985.

[20] R. F. Grimble, "Nutrition and cytokine action," Nutrition Research Reviews, vol. 2, pp. 193-210, 1990.

[21] S. H. Murch, "Inflammatory mediators and suppression of growth in paediatric chronic IBD," in Inflammatory Bowel Diseases, G. N. J. Tytgat, J. F. W. M. Bartelsman, and S. J. H. van Deventer, Eds., Kluwer Academic, Dordrecht, The Netherlands, 1995.

[22] M. E. Kanof, A. M. Lake, and T. M. Bayless, "Decreased height velocity in children and adolescents before the diagnosis of Crohn's disease," Gastroenterology, vol. 95, no. 6, pp. 15231527, 1988.

[23] D. R. Homer, R. J. Grand, and A. H. Colodny, "Growth, course, and prognosis after surgery for Crohn's disease in children and adolescents," Pediatrics, vol. 59, no. 5, pp. 717-725, 1977.

[24] J. Markowitz, K. Grancher, J. Rosa, H. Aiges, and F. Daum, "Growth failure in pediatric inflammatory bowel disease," Journal of Pediatric Gastroenterology and Nutrition, vol. 16, no. 4, pp. 373-380, 1993.

[25] M. Azcue, M. Rashid, A. Griffiths, and P. B. Pencharz, "Energy expenditure and body composition in children with Crohn's disease: effect of enteral nutrition and treatment with prednisolone," Gut, vol. 41, no. 2, pp. 203-208, 1997.

[26] K. J. Motil, R. J. Grand, L. Davis-Kraft, L. L. Ferlic, and E. O. Smith, "Growth failure in children with inflammatory bowel disease: a prospective study," Gastroenterology, vol. 105, no. 3, pp. 681-691, 1993.

[27] M. T. Saha, T. Ruuska, P. Laippala, and H. L. Lenko, "Growth of prepubertal children with inflammatory bowel disease," Journal of Pediatric Gastroenterology and Nutrition, vol. 26, no. 3, pp. 310-314, 1998.

[28] T. A. Sentongo, E. J. Semeao, D. A. Piccoli, V. A. Stallings, and B. S. Zemel, "Growth, body composition, and nutritional status in children and adolescents with Crohn's disease," Journal of Pediatric Gastroenterology and Nutrition, vol. 31, no. 1, pp. 33-40, 2000.

[29] B. S. Kirschner, "Growth and development in chronic inflammatory bowel disease," Acta Paediatrica Scandinavica, Supplement, vol. 79, no. 366, pp. 98-104, 1990.

[30] J. J. Lee, J. C. Escher, M. J. Shuman et al., "Final adult height of children with inflammatory bowel disease is predicted by parental height and patient minimum height Z-score," Inflammatory Bowel Diseases, vol. 16, no. 10, pp. 1669-1677, 2010.

[31] A. Sawczenko, A. B. Ballinger, M. O. Savage, and I. R. Sanderson, "Clinical features affecting final adult height in patients with pediatric-onset crohn's disease," Pediatrics, vol. 118, no. 1, pp. 124-129, 2006.

[32] A. M. Griffiths, P. Nguyen, C. Smith, J. H. MacMillan, and P. M. Sherman, "Growth and clinical course of children with Crohn's disease," Gut, vol. 34, no. 7, pp. 939-943, 1993.

[33] A. Sawczenko, A. B. Ballinger, N. M. Croft, I. R. Sanderson, M. O. Savage, and R. A. Van Hogezand, "Adult height in patients 
with early onset of Crohn's disease," Gut, vol. 52, no. 3, pp. 454-455, 2003.

[34] A. Paerregaard and F. Uldall Urne, "Anthropometry at the time of diagnosis in Danish children with inflammatory bowel disease," Acta Paediatrica, International Journal of Paediatrics, vol. 94, no. 11, pp. 1682-1683, 2005.

[35] A. Ballinger, "Fundamental mechanisms of growth failure in inflammatory bowel disease," Hormone Research, vol. 58, supplement 1, pp. 7-10, 2002.

[36] M. Enomoto, H. O. Pan, A. Kinoshita, Y. Yutani, F. Suzuki, and M. Takigawa, "Effects of tumor necrosis factor $\alpha$ on proliferation and expression of differentiated phenotypes in rabbit costal chondrocytes in culture," Calcified Tissue International, vol. 47, no. 3, pp. 145-151, 1990.

[37] F. De Benedetti, T. Alonzi, A. Moretta et al., "Interleukin 6 causes growth impairment in transgenic mice through a decrease in insulin-like growth factor-I. A model for stunted growth in children with chronic inflammation," Journal of Clinical Investigation, vol. 99, no. 4, pp. 643-650, 1997.

[38] A. B. Ballinger, O. Azooz, T. El-Haj, S. Poole, and M. J. G. Farthing, "Growth failure occurs through a decrease in insulin-like growth factor 1 which is independent of undernutrition in a rat model of colitis," Gut, vol. 46, no. 5, pp. 694-700, 2000.

[39] A. Sawczenko, O. Azooz, J. Paraszczuk et al., "Intestinal inflammation-induced growth retardation acts through IL-6 in rats and depends on the -174 IL-6 G/C polymorphism in children," Proceedings of the National Academy of Sciences of the United States of America, vol. 102, no. 37, pp. 13260-13265, 2005.

[40] J. Baker, J. P. Liu, E. J. Robertson, and A. Efstratiadis, "Role of insulin-like growth factors in embryonic and postnatal growth," Cell, vol. 75, no. 1, pp. 73-82, 1993.

[41] E. Wine, S. S. Reif, E. Leshinsky-Silver et al., "Pediatric Crohn's disease and growth retardation: the role of genotype, phenotype, and disease severity," Pediatrics, vol. 114, no. 5, pp. 1281-1286, 2004.

[42] J. J. Lee, J. B. Essers, S. Kugathasan et al., "Association of linear growth impairment in pediatric Crohn's disease and a known height locus: a pilot study," Annals of Human Genetics, vol. 74, no. 6, pp. 489-497, 2010.

[43] A. Ferguson and D. M. Sedgwick, "Juvenile onset inflammatory bowel disease: height and body mass index in adult life," British Medical Journal, vol. 308, no. 6939, pp. 1259-1263, 1994.

[44] A. B. Ballinger, M. O. Savage, and I. R. Sanderson, "Delayed puberty associated with inflammatory bowel disease," Pediatric Research, vol. 53, no. 2, pp. 205-210, 2003.

[45] S. B. Sondike, E. McGuire, and S. Kugathasan, "Weight status in pediatric IBD patients at the time of diagnosis: effects of the obesity epidemic," Journal of Pediatric Gastroenterology and Nutrition, vol. 39, supplement 1, p. S317, 2004.

[46] M. D. Long, W. V. Crandall, I. H. Leibowitz et al., "Prevalence and epidemiology of overweight and obesityin children with inflammatory bowel disease," Inflammatory Bowel Diseases. In press.

[47] M. Kusunoki, G. Moeslein, Y. Shoji et al., "Steroid complications in patients with ulcerative colitis," Diseases of the Colon and Rectum, vol. 35, no. 10, pp. 1003-1009, 1992.

[48] R. Gokhale, M. J. Favus, T. Karrison, M. M. Sutton, B. Rich, and B. S. Kirschner, "Bone mineral density assessment in children with inflammatory bowel disease," Gastroenterology, vol. 114, no. 5, pp. 902-911, 1998.
[49] J. E. Compston, "Management of bone disease in patients on long term glucocorticoid therapy," Gut, vol. 44, no. 6, pp. 770$772,1999$.

[50] J. S. Hyams and D. E. Carey, "Corticosteroids and growth," Journal of Pediatrics, vol. 113, no. 2, pp. 249-254, 1988.

[51] J. L. Franklin and H. H. Rosenberg, "Impaired folic acid absorption in inflammatory bowel disease: effects of salicylazosulfapyridine (Azulfidine)," Gastroenterology, vol. 64, no. 4, pp. 517-525, 1973.

[52] B. Feagan, J. Rochon, R. N. Fedorak et al., "Methotrexate for the treatment of Crohn's disease. The North American Crohn's Study Group Investigators," The New England Journal of Medicine, vol. 332, pp. 292-297, 1995.

[53] A. S. Day, K. E. Whitten, M. Sidler, and D. A. Lemberg, "Systematic review: nutritional therapy in paediatric Crohn's disease," Alimentary Pharmacology and Therapeutics, vol. 27, no. 4, pp. 293-307, 2008.

[54] R. B. Heuschkel, C. C. Menache, J. T. Megerian, and A. E. Baird, "Enteral nutrition and corticosteroids in the treatment of acute Crohn's disease in children," Journal of Pediatric Gastroenterology and Nutrition, vol. 31, no. 1, pp. 8-15, 2000.

[55] A. D. Levin, V. Wadhera, S. T. Leach et al., "Vitamin D deficiency in children with inflammatory bowel disease," Digestive Diseases and Sciences, vol. 56, no. 3, pp. 830-836, 2011.

[56] O. Borrelli, C. Bascietto, F. Viola et al., "Infliximab heals intestinal inflammatory lesions and restores growth in children with Crohn's disease," Digestive and Liver Disease, vol. 36, no. 5, pp. 342-347, 2004.

[57] D. M. Sinitsky, D. A. Lemberg, S. T. Leach, T. D. Bohane, R. Jackson, and A. S. Day, "Infliximab improves inflammation and anthropometric measures in pediatric Crohn's disease," Journal of Gastroenterology and Hepatology, vol. 25, no. 4, pp. 810-816, 2010.

[58] T. D. Walters, A. R. Gilman, and A. M. Griffiths, "Linear growth improves during infliximab therapy in children with chronically active severe Crohn's disease," Inflammatory Bowel Diseases, vol. 13, no. 4, pp. 424-430, 2007.

[59] S. Malik, S. Wong, J. Bishop et al., "Improvement in growth of children with crohn disease following anti-TNF- $\alpha$ therapy can be independent of pubertal progress and glucocorticoid reduction," Journal of Pediatric Gastroenterology and Nutrition, vol. 52, no. 1, pp. 31-37, 2011.

[60] U. Vespasiani Gentilucci, R. Caviglia, A. Picardi et al., "Infliximab reverses growth hormone resistance associated with inflammatory bowel disease," Alimentary Pharmacology and Therapeutics, vol. 21, no. 9, pp. 1063-1071, 2005.

[61] V. Crombé, J. Salleron, and G. Savoye, "Long-term outcome of treatment with Infliximab in Pediatric-onset Crohn's disease: a population-based study," Inflammatory Bowel Diseases. In press. 


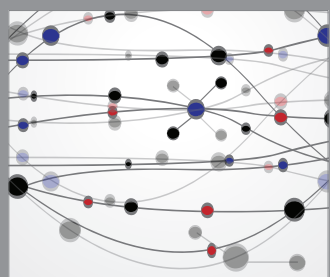

The Scientific World Journal
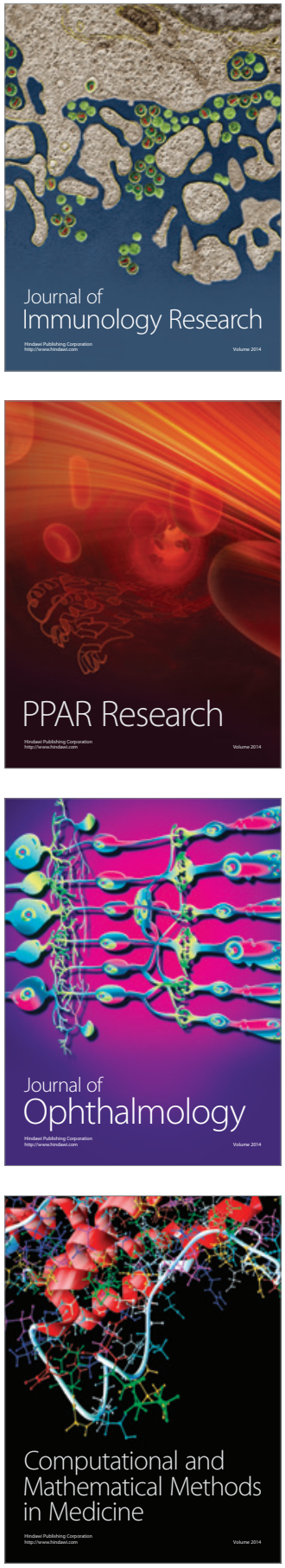

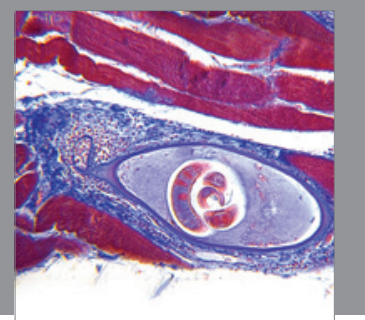

Gastroenterology

Research and Practice
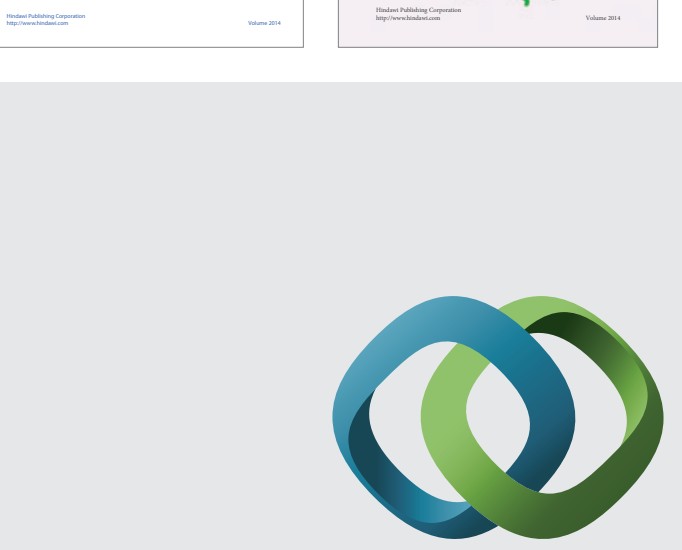

\section{Hindawi}

Submit your manuscripts at

http://www.hindawi.com
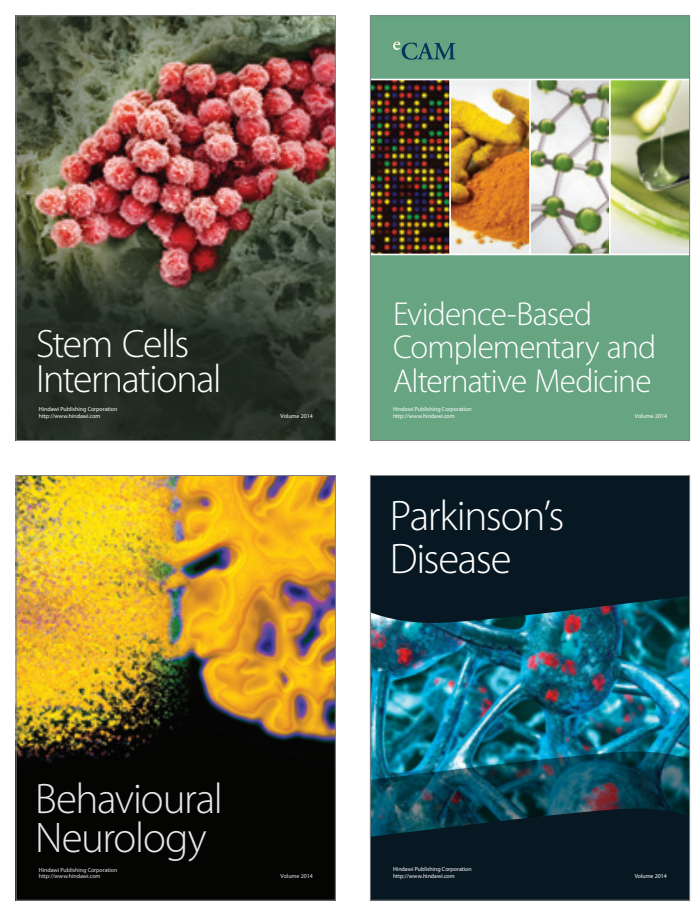

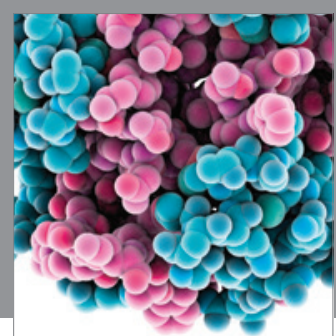

Journal of
Diabetes Research



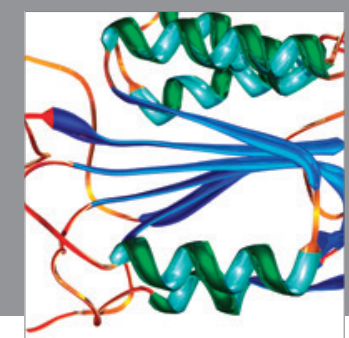

Disease Markers
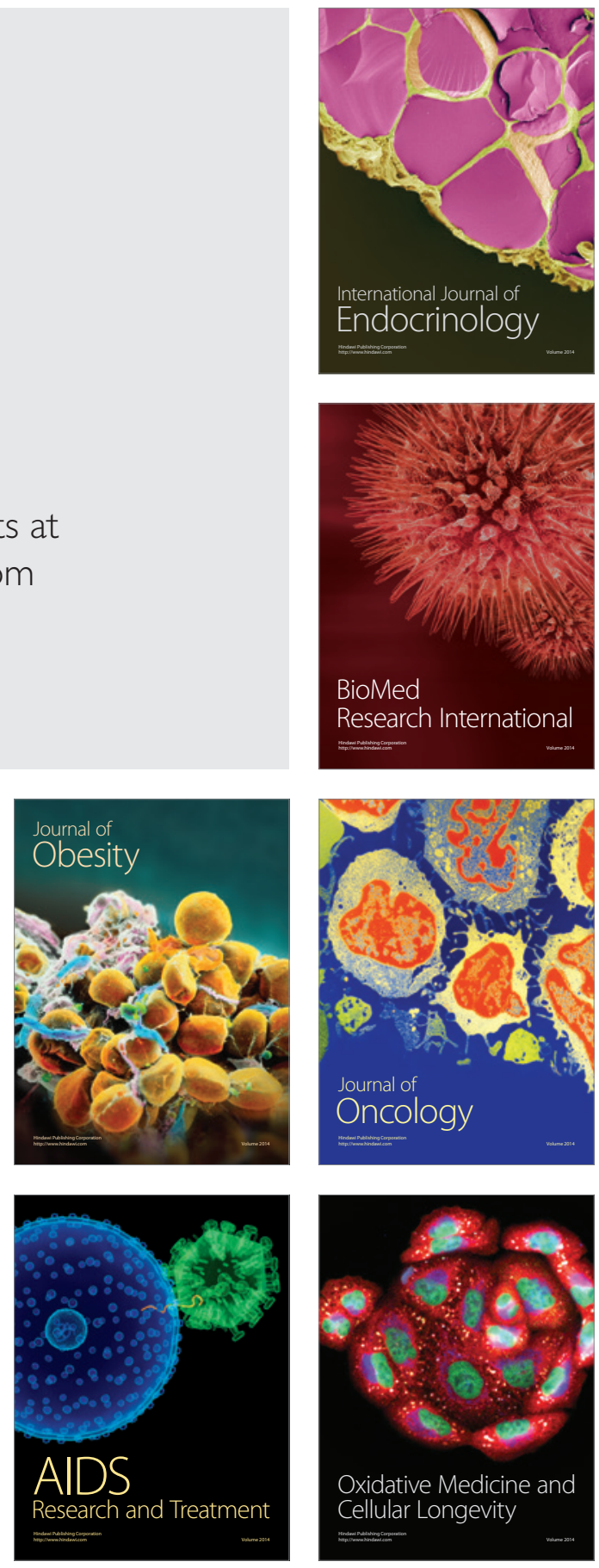